\title{
TRANSLATION INDUSTRY IN INDIA: TRENDS AND PROSPECTS
}

\section{Biswadip Gogoi}

\begin{abstract}
To many, it may come as a shock that in 2013 itself the translation industry in India was as big as a billion dollar (6500 Cr approx) market. Without any doubt, it is one of the fastest growing sectors in terms of economy, increased from US\$40 million in 2007 to US\$900 million in 2013. The industry thrives on the ever-increasing demands of language content-creation and content-consumption in wide range of disciplines, from Information Technology to Manufacturing, Medicine to Advertising etc. Creation of digital content through translation and ensuring their availability across platforms, in a greater way, is instrumental in accelerating the enormous growth.
\end{abstract}

This paper aims to deliberate the nature, current trends and scopes of the existing translation market in the light of various surveys and analysis presented by professionals and market analysts from different perspectives. It would further reflect upon the impact and contribution to the language community in terms of economy.

Keywords: translation industry, Indian languages, translation and technology, software localisation, content-creation and contentconsumption, digital divide 


\section{India and its linguistic plurality}

How many languages are spoken by the 1.25 billion population of India? It is a very complex question indeed. The official count by Census of India (2001) is 122 languages ${ }^{1}$, while Ethnologue counts it to be 454 . $^{2}$ The survey recently conducted by People's Linguistic Survey of India (PLSI) found that 780 languages $^{3}$ are being used in the country. Some languages documented during the survey are so rare that the number of speakers does not even reach the double digit. In such a scenario, for many Indians, there is no option other than to be multilingual. Census of India reports also indicates another very interesting fact - the number of English Speakers in India. While English is the primary language for barely quarter of a million people ( 0.23 million to be precise), more than 86 million people listed it as their second language and another 39 million as their third language. The total number of English speakers in India adds ups to be more than 125 million, which is more than twice the United Kingdom's population. But, still this is just $10 \%$ of the total population of India.

22 major Indian languages are listed in the VIII schedule of the Constitution of India and they are spoken by more than $96 \%$ of the total population with the following language-wise distribution: Hindi - 41.03\%, Bengali - 8.11\%, Telugu - 7.19\%, Marathi $-6.99 \%$, Tamil - 5.91\%, Urdu - 5.01\%, Gujarati - 4.48\%, Kannada - 3.69\%, Malayalam - 3.21\%, Odia/Oriya - 3.21\%, Punjabi - 2.83\%, Assamese - 1.28\%, Maithili - 1.18\%, Santhali - 0.63\%, Kashmiri - 0.54\%, Nepali - 0.28\%, Sindhi - 0.25\%, Konkani - 0.24\%, Dogri - 0.22\%, Manipuri - 0.14\%, Bodo - 0.13\% and Sanskrit - 0.01\%. ${ }^{4}$ This indicates that more than 750 languages are spoken by less than $4 \%$ of the country's population. Such a linguistic diversity of India acts as an underlying current for the fast growing translation industry.

\section{Language and Netizens}

In terms of accessibility to internet and computer technology in 2014, India is in the third position with 243 million 
internet users, after China and USA. But, this is just $19.19 \%$ of the total population whereas world average stands at $40.4 \%$. India's neighbour China is far ahead with $46.03 \% .^{5}$ Though, in recent times, technology is rapidly entering into the life of common masses, computer and internet access is still a far cry to a large number of Indians. Moreover, more than $80 \%$ of contents available in internet are in English, and as mentioned, only $10 \%$ of the total Indian population possess English knowledge. Therefore, it is very important to translate content, localise products into Indian Languages to ensure a wider reach and to arrest the sprawling 'Digital Divide'.

\section{Government Initiatives}

With an aim to eliminate the digital divide, from time to time, Government of India has taken various steps. One such step was setting-up Technology Development for Indian Languages (TDIL) in 1991. TDIL has been mandated to bridge the digital divide by developing IT tools in local languages in India. Since then, TDIL has been collaborating with various organisations like C-DACs, IITs and IIITs for developing Indian language computing resources, processing systems, tools and translation support systems and localization of software for Indian languages, etc. In 2008, as per the recommendation of National Knowledge commission (NKC), Government of India launched National Translation Mission (NTM) with an objective to establish translation as an industry in India. NTM has been collaborating with various institutes, private publishers, universities etc by providing financial and academic assistance for bringing out translations of pedagogic materials (used in undergraduate and post graduate level of studies) in Indian languages in order to reach out to the section of students with limited English knowledge.

\section{Translation industry - present scenario}

The translation industry that exists in India is not visible at all from the outside. Although the professionals associated with it 
may have a rough idea, a panoramic view might still not be available. From the bits and pieces of data available on various platforms, it may not be an exaggeration to claim that the translation industry could be one of the most sought after destination, for not only translation professionals in India, but also for IT and management professionals. Texts or contents from a wide range of subjects are being translated from one language to another: Aerospace, Agriculture, Automotive, Architecture, Advertising, Manufacturing and Industrial, Art, Literary, Biotechnology, Defence, Electronics, Finance and Banking, Energy, Engineering, Entertainment, Environmental, Fashion, Government, Healthcare, Higher Education, Homeopathy, Hospitality, Information technology, Insurance, Internet and E-commerce, Investment and Securities, Journalism, Law and Legal, Logistics, Management, Real estate, Religion, Communications, Metallurgy and casting, Oil, Medical and Life Sciences, Pharmaceutical, Safety, Security, Social sciences, Software, Sports, Telecommunications, Tourism etc are just to name a few.

At present, hundreds of companies and agencies are providing translation services in India. The nature of services provided by these companies is also very diverse. For example, Content development and management, Copywriting, Desktop publishing (DTP), Document translation, Editing, Interpreting, Language training, Linguistic testing, Localization, QA Testing, Scriptwriting, Subtitling, Technical writing, Telephone interpreting, Training, Transcriptions, Translation, Typesetting, Voiceover, dubbing and so on.

\section{Localisation - the next big thing?}

Translation is one of the major parts in the localisation process. Localisation is commonly defined as adapting a product to a specific market. It includes translation as well as adaptation of graphics, currencies, dates, addresses, phone numbers and many other factors and parameters. It is said that with the emergence of software localisation in early 1980 's, the translation industry got 
a huge push. Initially, most of the companies including software developers started either in-house translation department, or outsourced the task of translations to individual translators. Immediately after, the increasing size and complexities of the localisation projects made them realise that they simply do not have sufficient time and expertise to manage the multilingual translation and localisation projects. It led to the formation of Multi-lingual Vendor (MLV). ${ }^{6}$ In a very short span of time, an outsourcing model was developed, and along with translation, the MLVs started to offer engineering, testing, desktop publishing, printing and other support services.

The translation industry in India involves - Publication, DTP, Content Creation, Translation, Repurposing, IT localisation etc. Among these, translation and localisation are the most happening fields with more and more MNCs entering in this market either as vendors or as clients. Among the vendors or MLVs operating in India, Lionbridge Technologies Pvt. Ltd., SDL India, WebDunia, Lyric Lab, Coral Knowledge Service, FidelTech are worth mentioning. Lionbridge Technologies was the first MLV to be set up as early as 1980 s, then named as INK. It was later renamed as Lionbridge Technologies and now is one of the biggest companies that specialises in management and translation of technical documentation and software. It also tops the list of biggest MLVs of the world in terms of revenue as per the market research group Common Sense Advisory (CSA) report. SDL is a British company having multiple offices in India, and now 4th biggest MLV in the world. Home grown MLVs like WebDunia, Lyric Lab, Coral Knowledge Service and FidelTech are expanding their footprint rapidly with professional and efficient handling of projects.

While discussing the chief reasons behind Multi-national companies' interest in localising their products into different world languages, Bert Esselink points out that business reasons aside, a number of companies are translating and localising their products for legal reasons. In many countries, such as some 
Baltic countries, importing or using products which are not in the country's native language is not permitted. Here, it will be worth mentioning about a survey conducted by CSA. According to their 2006 report - "Can't Read, Won't Buy", 72.4\% respondents said that they are more likely to buy products with information written in their native languages.

\section{Market Scenario - Global \& India}

The global translation market is estimated to be 33.5 billion USD in 2012 and 34.7 billion USD in 2013 with a growth rate of about $5.13 \%$. The market is expected to expand further and reach 43 billion USD in 2016. ${ }^{7}$ The present market is mostly controlled by MLVs based either in Europe or in North America. In 2012, the continent-wise break up was: North America - 34.85\%, South America - 0.63\%, Europe - 49.38\%, Asia - 12.88\%, Africa $0.27 \%$ and Oceania $-2.00 \%$. For Asia, the positive point is that the market share was increased from $7.43 \%$ in 2011 to $12.88 \%$ in 2012.

One of the major reasons why the translation and localisation industry first flourished in Europe, especially in Western Europe, is that the MNCs first started to localise their products into European languages, such as, French, German, Spanish, Italian etc. In Asia, localisation started in Chinese and Japanese, followed by Hindi, the biggest language in India. The scenario has changed quickly, and now MNCs are getting their products localised in most of the 22 languages listed in the VIII schedule of the Constitution of India, with special emphasis on 10-12 major Indian languages with most number of speakers.

\section{Indian Market - A panoramic view}

India is considered to be one of the fastest growing technology markets, and accordingly, many companies are adopting various methods to expand their presence. Tech giant Microsoft Corporation, known for their Operating System Windows and popular Office Suite - Microsoft Office, is one 
among the major players getting their products localised in Indian languages. At present, Language Interface Packs (LIPs) ${ }^{8}$ for Microsoft products are available in Assamese, Bengali, Gujarati, Hindi, Kannada, Konkani, Marathi, Malayalam, Nepali, Punjabi, Telugu and Tamil. Installing these free LIPs, downloadable from Microsoft website, will enable users to use Windows and Microsoft Office products in their own languages. It is worth mentioning that Microsoft Windows and Office products are also available in Sindhi and Urdu, but localisation in these two languages are not undertaken in India. Currently, South Korean Mobile and PC marker Samsung is investing a huge sum of money to localise their mobile phone user-interface (UI) in some major Indian languages.

A recent addition to the MNCs list that are localising products into Indian languages to attract more and more users is Chinese mobile phone maker - Xiaomi. Its Indian subsidiary Xiaomi Technology India Private Limited is, at present, localising their popular products, especially mobile phone UI, popularly known as MIUI, to 10 Indian languages.

Besides these, tech companies like, Google, Adobe, LG, Sony, Meizu, Oppo etc are also localising their products into Indian languages in recent times. With every single day new companies joining the bandwagon, the translation market in India is expanding at an accelerated speed.

Publishing Companies are also contributing towards the expansion of language and translation market in a big way. Big publishing houses like Pearson Education, Oxford University Press etc have been testing the water of Indian language publishing sector from time to time. Sage India, in 2015, launched a new project called 'SAGE Bhasha - The Indian Language Publishing Program' under which books in Indian languages will be published. "SAGE Bhasha is a natural extension of our English language publishing program. Our core focus is social science publishing and in business and management and we plan to extend this vision and focus into the regional language program," says Vivek 
Mehra, Managing Director and CEO of SAGE India. ${ }^{9}$

In terms of revenue, the Indian translation Industry is just $19 \%$ of the Asian Industry. It is estimated that in 2013 , it was as big as a billion USD market. If translated into Indian rupees, it would be a whopping $6500 \mathrm{Cr}^{10}$ Without any doubt, it is one of the fastest growing sectors in terms of economy - 40 million USD in 2007, 100 million USD in 2010, 500 million USD 2012 and 900 million USD in 2013. This indicates that it has witnessed a staggering $200 \%$ growth in 2012-13.

\section{Translation related services as profession?}

Although translation industry has displayed immense optimism in India, unless the government takes necessary steps to organise it better, its prospect perhaps will be derailed. In India, unlike other developed nations such as USA, UK, Canada, Australia, China or Japan, freelancing of translation jobs are not considered to be very stable. This is largely because of the irregular flow of work. It can be estimated from various sources available that in USA, a freelance translation professional can earn an average of 55,000 USD per year, which is almost equivalent to the annual salary of a middle school teacher in USA. Likewise, a translator can earn an average of 55,000 dollars in Australia and 50,000 in Canada. Data about earning of a freelance translator in India is simply not available. But from personal experience and webbased study, it would be safe to estimate that a serious freelance translator in India can easily earn as much as Rs.15,000 - Rs.20,000 a month. The earning of a full-time translator may even go higher than this.

\section{Use of Technology}

Adoption of technology among organizations and individual translators differs significantly. Because of the cost and effort required to build and maintain the translation tools, only the larger organizations show interest in investing enough money 
to develop or acquire necessary technology and tools.

Besides traditional tools such as, dictionaries, glossaries, thesaurus etc, the usage of Computer-assisted translation (CAT) tools is increasing rapidly in order to improve productivity. The main function of a CAT tool is to save or store the translation units in a database, called Translation Memory (TM), so that they can be re-used for any other text, or even in the same text. CAT tools also uses term-bases, kind of e-glossary that helps the translator to maintain consistency across translations. Some popular CAT tools are - SDL Trados, SDL Passalo, Fluency, OmegaT, Déja Vù, Wordfast etc. These tools are mostly used offline. With the growing user base of internet and internet based services, online tools or platforms for are gaining momentum and becoming popular among the translation companies as well as translators. One such 'Localization Management Platform' is Crowdin. ${ }^{11}$ This Ukraine originated platform, started in 2009, aims at 'mobile apps, web, desktop software and related assets' localisation. Companies like Microsoft designed different tools to be used its own product localisation such as Loc Studio, Dr. Know, Leaf Professionals etc. Here, Leaf Professionals is an online tool where as other two are offline.

There are advantages and disadvantages of both online and offline tools. Offline tools are installable and licenses need to be bought by the users. They are generally very expensive but once bought, user can create their own memory or term-bases for future use. On the other hand, to use online tools or platforms such as Crowdin, there is no need to invest money. The company that hosts and manages projects would pay for hosting a project and translator can log in to the workspace. The disadvantage is that the translator's access to the workspace, term-base or memory depends on the host. Once they are out of the project, they may lose access to all the translation resources. Leaf Professionals from Microsoft also work mostly same way, but users need to use an installable file through which they can connect to the work server. 
Industry giant Lionbridge Technologies has introduced cloud based translation platform - Lionbridge Translation Workspace. This "cloud-based translation productivity platform, Lionbridge Translation Workspace streamlines website translation processes through real-time translation memory (TM), terminology management, and online review capabilities. It also significantly boosts efficiencies to help our translation experts reduce project turnaround times and costs-while delivering the highest levels of language consistency and translation quality."12

Popularity of Machine Translation (MT) has also increased substantially. Quest for building MT systems that work with Indian languages started 20 years back in 1995 in the form of Anusaaraka Systems in IIT Kanpur. Thereafter, many MT systems such as MANTRA MT (1999), MAT (2002), Shakti (2003), OMTrans (2004), The MaTra System (2004, 2006), Sampark System: Automated Translation among Indian Languages (2009), ANGLABHARTI (2001), AnglaHindi (2003), Anubharti I \& II $(1995,2004)$ are developed by various organisations and individuals.

Global language translation software market too brings ray of hope to the industry. From the beginning of the present decade, the market shows rapid growth. The global market was estimated to be 575.5 million USD (approx) in 2010 and in 2012 it reached 1.6 billion USD (approx). Market analysts predict further growth and estimates that in 2019, it would reach 6.9 billion USD. No doubt that there has been considerable improvement in the quality of machine translation and translation memory, but these tools are yet to be fully adopted by the industry.

\section{Challenges and what lies ahead?}

The main issues that are hampering the growth of translation industry in India are - fragmented nature of the industry; low penetration of computers \& internet; lack of universal standards for scripts and fonts, input methods and transliteration; limited availability of software and fonts; low availability of local 
language content; lack of formal language-based IT training; lack of accreditation for translators and companies; non-payment to translator or language professionals etc.

As mentioned above, the Indian translation industry is definitely fragmented. Lack of proper regulations has allowed the mushrooming of translation companies in India in recent times. In 2002, only 12 to 20 vendors were operating in India's local-language IT market, as reported by Microsoft, but in last 1012 year, the number has increased manifold. Therefore, creating a single platform for all the companies or agencies that offers translation services is the need of the day.

There is also a need to increase access to computer and internet. A recent survey conducted in Karnataka ${ }^{13}$ does not show very promising results. The report states that $81.40 \%$ people of Karnataka own mobile phones while in Bangalore, it is $82.71 \%$. Regarding computer and internet accessibility, mere $17.21 \%$ Bangaloreans have access to both and $6.32 \%$ does own a computer but does not have access to internet. The state figures stands at $10.40 \%$ having access to both computer and internet and $5.26 \%$ have access to only computer. If the 'IT Hub' or 'Silicon Valley of India' Bangalore stands so low in terms of availability of computer and internet, the situation of smaller cities and rural areas are easily imaginable. Along with increasing accessibility to computer and internet, there is also an urgent need to standardize scripts, fonts, input systems and transliteration methods in Indian languages. Though, at present Unicode is being considered as standard for localisation and web-based texts, the publishing sector, including large part of Media is still stuck with other proprietary fonts. When enquired with Indian language publishing professionals, the reason given is the unavailability of different Unicode fonts for Indian languages. Also, until recently, DTP and Designing software did not support Unicode fonts for these languages.

In a recent interview, Sandeep Menon of Google India said, "Only one in six Indians know enough English to surf the 
web in that language. But there are few web pages in Hindi or India's 21 other official languages. There are more web pages in Estonian than in Hindi." ${ }^{14}$ As an aside, it is interesting to note that the number of native speakers of Estonian language is just 1.2 million while each of the 22 languages of India, barring Sanskrit has more than 1.2 million speakers.

Considerable dearth of trained human resources in translation industry is also responsible in slowing down the growth of the industry. Not a mere language, linguistics or translation studies degree can produce a translation professional. With technologies changing each day, the professionals need to update their knowledge of technologies. Therefore, necessity of a formal training is undeniable. Public educational institutions in India are lacking in this front. However, a few private companies like Oracle Financials India do conduct online course on localisation.

Another major issue is the lack of accreditation for translators as well as companies. Till now, no government or private agencies have developed any accreditation system which will enable the industry to identify skilled human resources. At present, all sorts of individuals, skilled or unskilled; and agencies, registered or unregistered are into translation business, thereby creating sub-standard contents or materials. Ghost companies are being created to exploit translators by not paying proper fee or remuneration. Recent steps taken by NTM could bring a welcoming change to the industry. NTM's reports mention that it has started piloting the methods and means of its nationwide Certification of Translators Programme. The certification module is being developed in collaboration with the National Accreditation Board for Certification Bodies (NABCB) of the Quality Council of India $(\mathrm{QCl})$ along the lines of the international standards set for Personnel Certification. Training of evaluators will be a major component of the Certification of Translators Programme, as a new system of grading translators will be introduced.

In spite of all the roadblocks, the translation industry in 
India has been growing at a very high rate. Market analyst and industry professional, Elanna Mariniello, Matthias Steiert and Afaf Steiert wrote, "As with any emerging market, there are still struggles to be overcome on the path toward India's future growth. These challenges include a perceived lack of organization, lack of professionalism and a continued effort to master the English language. Despite these challenges, the statistics, reports, articles and associations all reflect the same defining factor: Growth."15

Indian translation industry still is in its nascent stage, and if appropriate steps are taken, in next 10 years, it will be able to provide livelihood to many budding translators. Good news is that, government has already started taking development of IT structure very seriously, which will eventually help people from rural areas. Huge IT infrastructure in terms of setting up of networks, financing rural cyber cafés and information are being created. Investment in e-governance is also truly phenomenal. Gyandoot, Community Information Centers (CICs), e-Seva, BangaloreOne, e-Chaupal are some example of such initiatives. A new government initiative Digital India is launched in July, 2015 with the 'vision to transform India into a digitally empowered society and knowledge economy.'16

With increasing demand for quality language professionals and translators, the estimation of NKC is proving to be true. In the Report to the Nation, 2006 - 2009 the NKC mentioned - "Going by the experiences of other countries, in a country like India with its many languages, as well as huge potential for foreign language translation the entire translation industry has the potential eventually to employ between 200,000 and half a million people."17

\section{NOTES}

1. Census of India report only includes languages with more than 10,000 speakers.

2. https://www.ethnologue.com/statistics/country [Data mined on 10-11-2015, 11:00 AM] 
3. Prof. Ganesh Devy, supervisor the PLSI said in an interview to Reuters.

4. Census of India, 2001

5. http://www.internetlivestats.com/internet-users/ [Data mined on 6-11-2015, 12:07 AM]

6. MLVs are public or private company that expertise in providing language and translation service in many languages

7. Estimated by Common Sense Advisory, a market research group.

8. LIPs are bundle of additional language files installed on the Windows operating system. The user can change the display language to view wizards, dialog boxes, menus, help topics, and other items in Windows in a different language. (www. microsoft.com)

9. Business Standard, 15th March, 2015

10. Same as 7

11. https://crowdin.com/

12. http://www.lionbridge.com/solutions/translation-workspace/

13. News report of a survey is conducted by Govt. of Karnataka, Bangalore Mirror, 29th September, 2015.

14. Business Insider, Singapore, 28th September, 2015

15. India: Many languages, one emerging market, MultiLingual, December 2011

16. http://www.digitalindia.gov.in/

17. Report to the Nation by NKC, Government of India 2006 2009, published in March, 2009 


\section{REFERENCES}

- Esselink, Bert. (2000), A Practical Guide to Localisation (Revised Edition), John Benjamins Publishing, ISBN 9789027219565

- Garje, G V; Kharate, G K. (2013), Survey of Machine Translation Systems in India, International Journal on Natural Language Computing (IJNLC) Vol. 2, No.4, October

- Khanna, Shruti. (2008), Training needs for the Localization Industry in India, A report prepared for the TechLink project. http://isg.urv.es/publicity/isg/projects/2007_techlink/

- Mariniello, Elanna; Steiert, Matthias; Steiert, Afaf. (2011), India: Many languages, one emerging market, MultiLingual, December

- Reports of National Knowledge Commission (NKC) and National Translation Mission (NTM)

- Survey reports from Common Sense Advisory

- Various websites, magazine and newspaper articles 